\title{
Long term trends in the sea surface temperature of the Black Sea
}

\author{
G. I. Shapiro ${ }^{1,2}$, D. L. Aleynik ${ }^{2,3}$, and L. D. $\mathrm{Mee}^{3}$ \\ ${ }^{1}$ School of Marine Science and Engineering, University of Plymouth, Plymouth, PL4 8AA, UK \\ ${ }^{2}$ P. P. Shirshov Institute of Oceanology, Moscow, Russia \\ ${ }^{3}$ Scottish Association for Marine Science, Scottish Marine Institute, Oban, PA37 1QA, UK
}

Received: 12 December 2009 - Published in Ocean Sci. Discuss.: 18 January 2010

Revised: 28 April 2010 - Accepted: 29 April 2010 - Published: 7 May 2010

\begin{abstract}
There is growing understanding that recent deterioration of the Black Sea ecosystem was partly due to changes in the marine physical environment. This study uses high resolution $0.25^{\circ}$ climatology to analyze sea surface temperature variability over the 20th century in two contrasting regions of the sea. Results show that the deep Black Sea was cooling during the first three quarters of the century and was warming in the last 15-20 years; on aggregate there was a statistically significant cooling trend. The SST variability over the Western shelf was more volatile and it does not show statistically significant trends. The cooling of the deep Black Sea is at variance with the general trend in the North Atlantic and may be related to the decrease of westerly winds over the Black Sea, and a greater influence of the Siberian anticyclone. The timing of the changeover from cooling to warming coincides with the regime shift in the Black Sea ecosystem.
\end{abstract}

\section{Introduction}

Europe's four regional seas (the Baltic, Black, Mediterranean and North Sea) have all suffered major ecological change in the past three decades. There is compelling evidence of degradation of marine habitats on the Black Sea shelves beginning in the mid-1970s (Mee et al., 2005). The causes of such catastrophic degradation of the Black Sea ecosystem have been frequently cited as eutrophication due to increased riverine nutrient load as a result of the Green Revolution (Zaitsev and Alexandrov, 1997) and the arrival of invasive species (Kideys, 2002). However, there is an increasing appreciation that current climate change can trigger a major response in the structure and function of marine ecosystems on a decadal timescale, as has been observed in various parts of

Correspondence to: G. I. Shapiro (gshapiro@plymouth.ac.uk) the World ocean including the North Atlantic and the North Sea (Reid et al., 2001) and the Mediterranean Sea (Conversi et al., 2009). Recent research demonstrates that changes in temperature, wind and river run-off may also play a role in changes of the Black Sea ecosystem (Daskalov, 2003; Oguz, 2005). Physical factors are also cited as contributing to the inter-decadal changes in chlorophyll concentrations in the open Black Sea (Yunev et al., 2007). Hence reliable information of long term trends in the physical environment is vital for our understanding of the changes in the Black Sea marine ecosystem. The western shelf is particularly important for marine life, whilst the central deep part of the sea is anoxic below about $200 \mathrm{~m}$ (Kideys, 2002).

The warming of the World Ocean over recent decades has been firmly established (e.g. Levitus et al., 2005, 2009 and references therein). In the Black Sea, studies of inter-annual variability of the physical properties are commonly restricted in their time coverage to the last 20 to 50 years, see e.g. (Kazmin et al., 2009 and references therein). Polonsky and Lovenkova (2004) gave a detailed analysis of SST variability and their possible causes over the period of 1960-1990, however their study was limited to a single transect across the Black Sea. Potential causes of temperature changes and their link with North Atlantic Oscillations were also discussed by Oguz (2005) and by Kazmin et al. (2009). Studies covering longer periods are mostly concerned with changes in the sea as a whole and are based on the analysis of the monthly/yearly mean Sea Surface Temperature (SST) derived from $1^{\circ} \times 1^{\circ}$ gridded data sets (see Oguz, 2005 and references therein), which in turn were obtained by optimal interpolation from $4^{\circ} \times 4^{\circ}$ or $2^{\circ} \times 2^{\circ}$ gridded observations (Rayner et al., 2003 and Stephens et al., 2002). With the exception of recent years when the satellite data become available (see e.g. Ginzburg et al, 2004; McQuatters-Gollop et al., 2008), historical data sets contain insufficient data to produce charts of monthly SST distributions with resolution adequate to separate the shelf and the deep sea regions.

Published by Copernicus Publications on behalf of the European Geosciences Union. 
Existing gridded data sets seem to be too coarse for the Black Sea, which is only $1150 \times 580 \mathrm{~km}$ in size. Rayner et al. (2003) note that care must be taken when using interpolated gridded data sets for studies of observed climatic variability, particularly in some data sparse regions, because of the limitations of the interpolation techniques.

The aim of this paper is to analyze temporal trends and long-term (on interannual to inter-decadal scale) changes of the SST during the 20th century over the contrasting shelf and deep sea regions using original individual observations rather than interpolated data sets. This is achieved by analyzing temperature anomalies instead of their absolute values, the method which allows to avoid some of the limitations inherent to the calculations based on interpolated data sets.

\section{Data and methods}

The source of data for this study is a combination of the sea surface temperature data subset from the World Ocean Database 2001 (WOD01) (Stephens et al., 2002), for the period 1900-2000, which includes 15517 individual stations, and the data set obtained from the Romanian Marine Research Institute (2362 stations covering the period 19632004).

Monthly air temperature data for the coastal stations in Odessa (period 1900-2000) and Yalta (1881-1990) were obtained from the Goddard Institute for Space Studies website http://data.giss.nasa.gov/gistemp/station_data/. The time series for North Atlantic Oscillation (NAO) Index for winter months (December to March) was obtained from the University of East Anglia Climatic Research Unit website http://www.cru.uea.ac.uk/ timo/datapages/naoi.htm (see also Jones et al., 1997). In contrast to previous Black Sea studies, the monthly temperature anomalies rather than the absolute values are used as indicators of temporal changes in Sea Surface Temperature. The benefit of using anomalies is that unlike the absolute temperatures, the SST anomalies are highly correlated at stations separated as far as $1200 \mathrm{~km}$ (Hansen and Lebedeff, 1987); this fact allows aggregating observational data over large areas of the Black Sea.

The time series of monthly SST anomalies for the shelf and deep parts of the Black Sea were obtained as follows: first the gridded climatic mean values for each calendar month were calculated at a high spatial resolution of $0.25^{\circ}$, then the SST anomalies at individual stations were calculated, which were then aggregated in time and space over selected areas as detailed below.

\subsection{Quality control}

The accuracy of all methods of measurement were well within $0.1^{\circ} \mathrm{C}$, which is significantly smaller than both natural variability of temperature in the Black Sea and statistical errors, hence there was no need for additional bias adjust-

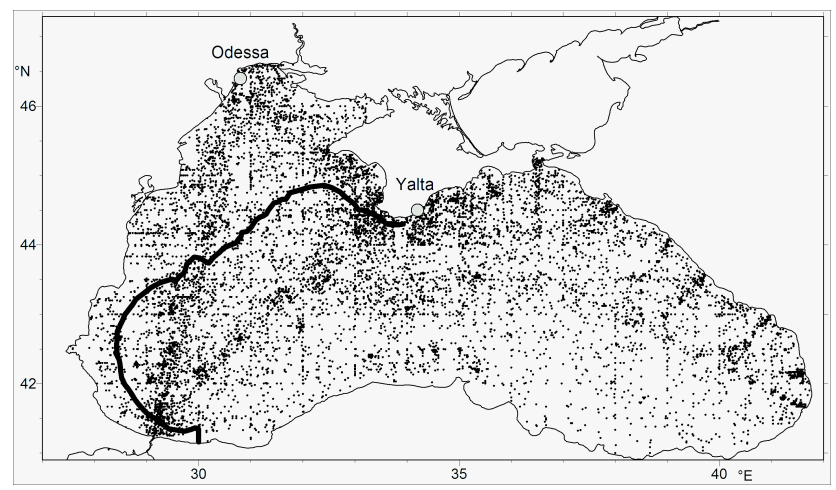

Fig. 1. Spatial distribution of the original measurements is shown. The solid line separates the western shelf (WS) and the deep sea (DS). Open circles indicate locations of the weather stations Odessa and Yalta.

ment (Folland and Parker, 1995). The distribution of available original data over the century is shown in Fig. 1. In order to eliminate erroneous data points, the combined data set from WOD01 and RMRI were subject to a quality control using a two- step procedure (Stephens et al., 2002): (1) coordinate check and (2) statistical check. During the first step a small number of stations showing their location on land were removed.

The remaining data were subdivided geographically into $0.25^{\circ}$ squares. Then the approximate values of the "firstguess" monthly mean states and standard deviations were calculated for all 12 calendar months and all $0.25^{\circ}$ degree squares. During the second step, the outliers, i.e. the data points with more than 6 standard deviations away from the mean, were removed from the data base. Following Willis et al. (2004) we have chosen 6 rather than a more usual 2.3 standard deviation range in order to keep enough data to analyse significant interannual variability of SST in the Black Sea. After cleaning, 17525 stations for the period 1910-2000 remained for further analysis, there were no recorded in-situ observations for the period 1900-1909 and during the war time.

\subsection{Climatic averages}

In calculation of climatologies, the uneven distribution of data in time and space is often the largest source of uncertainty (Lozier, 1995). The horizontal distribution of stations in the Black Sea is far from uniform. The highest density of stations occurs in the western and north-eastern parts of the sea (see Fig. 1), with sparser distribution of stations in the south-east. The widest and most productive shelf is in the north-western of the Black Sea, which is covered by a dense net of sampling stations. In addition to spatial inhomogenities, the distribution of stations varies also over time due to political and socio-economic factors (Fig. 2). It is worth noting that in the 1920 -s there was a reasonable amount of 


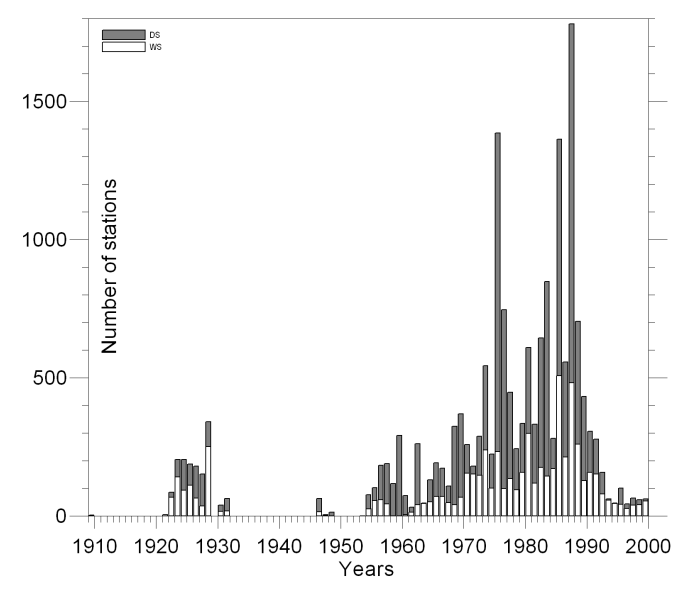

Fig. 2. The bar-chart showing distribution of the number of SST observations over 20th century. Only quality controlled data are included in this histogram and all following figures. Total height of the bars represent the total number of sampling points, open parts represent measurements taken on the shelf. There were no recorded measurements between 1900 and 1910 and during the war-time.

measurements, which could be used to recover the trends in temporal variations. The number of observations also varies from month to month (Fig. 3).

It would be ideal to create gridded data sets for all months and all years on a high density grid and infer both climatic means and interannual variability from these mapped data. With the available historical data sets for the Black Sea, there is not enough data to fill all or even the majority of individual small grid-boxes. The increase in the size of grid-boxes would reduce statistical errors but it would lead to the loss of resolution and hence greater errors when calculating anomalies, i.e. deviation of the actual observations from the mean state. This source of error is particularly noticeable at the shelf - deep sea borders, where mean values in one region can be contaminated with observations from a physically different region. Grouping together the data over a larger (than one month) period of time, e.g. by seasons also reduces the statistical errors but leads to the loss of temporal resolution.

One way to achieve a reasonable balance between resolution and accuracy is to use an adaptive rather than a fixed size grid (Lozier et al., 1995; Shapiro, Meschanov, 1996) where grid-boxes that contained small amounts of data were consolidated. Similar idea was used in recent study by Willis et al. (2004) who used a weight function to automate the process. Due to temporal inhomogenity of data the monthly means could be biased towards the years in which greater amounts of data are available. In order to reduce this source of error we used the adjustment for sampling density in grid boxes similar to that used by Jones et al. (2001), namely first aggregating data into individual monthly bins and then calculating the overall climatic average.

For this study all data were segmented into 12 monthly

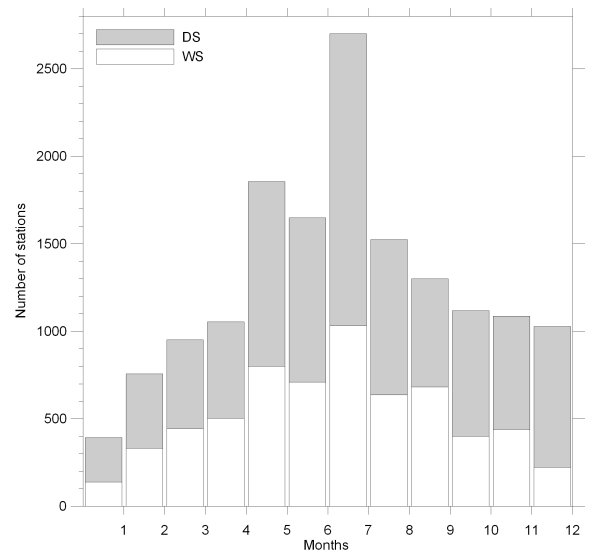

Fig. 3. The bar-chart showing distribution of the number of observations over calendar months (1=January). Open parts of the bars represent measurements taken on the shelf.

blocks and SST climatologies were produced by gridding original observations onto a dense $0.25^{\circ}$ latitude-longitude grid for each calendar month. A version of the adaptive grid method (Shapiro and Meschanov, 1996) was applied where the elementary area over which averages were computed changed its size depending on the density of available observations. The mapping procedure used a two-scale covariance function $C(r)$ in the form introduced by Willis et al. (2004)

$C(r)=\theta\left(r / r_{\mathrm{s}}\right) \cdot \exp \left[-\left(\frac{r}{r_{\mathrm{d}}}\right)^{2}\right]$,

where $r$ is the distance between the centre of the square and the actual observation, $r_{\mathrm{s}}$ is the maximum radius of influence (i.e. maximum search radius), $r_{\mathrm{d}}$ is the decorrelation radius, and the truncation function $\theta(x)$ is defined as $\theta(x)=1$ if $x<1$ and $\theta(x)=0$ if $x>1$. We have found that for the present study the best balance between accuracy and resolution is obtained with the following parameters: $r_{\mathrm{s}}=100 \mathrm{~km}$ and $r_{\mathrm{d}}=25 \mathrm{~km}$.

The chosen value of the search radius was approximately half of that used by Boyer et al. (2005) and hence gives a better spatial resolution. The mapping procedure was applied at every point on the $0.25^{\circ}$ rectangular grid to produce monthly composite time series $T_{\mathrm{p}}$ using the equation

$T_{\mathrm{p}}(x, y, m, i)=\frac{\sum_{\mathrm{k}} C\left(r_{\mathrm{k}}\right) T\left(x_{\mathrm{k}}, y_{\mathrm{k}}, m, i\right)}{\sum_{\mathrm{k}} C\left(r_{\mathrm{k}}\right)}$,

where $x, y$ are the coordinates of the grid node; $x_{\mathrm{k}}, y_{\mathrm{k}}-$ are the co-ordinates of the original observations; $i$ is the year number, $i=1$ being the year 1901, $m$ is the calendar month number, $m=1$ being January. 


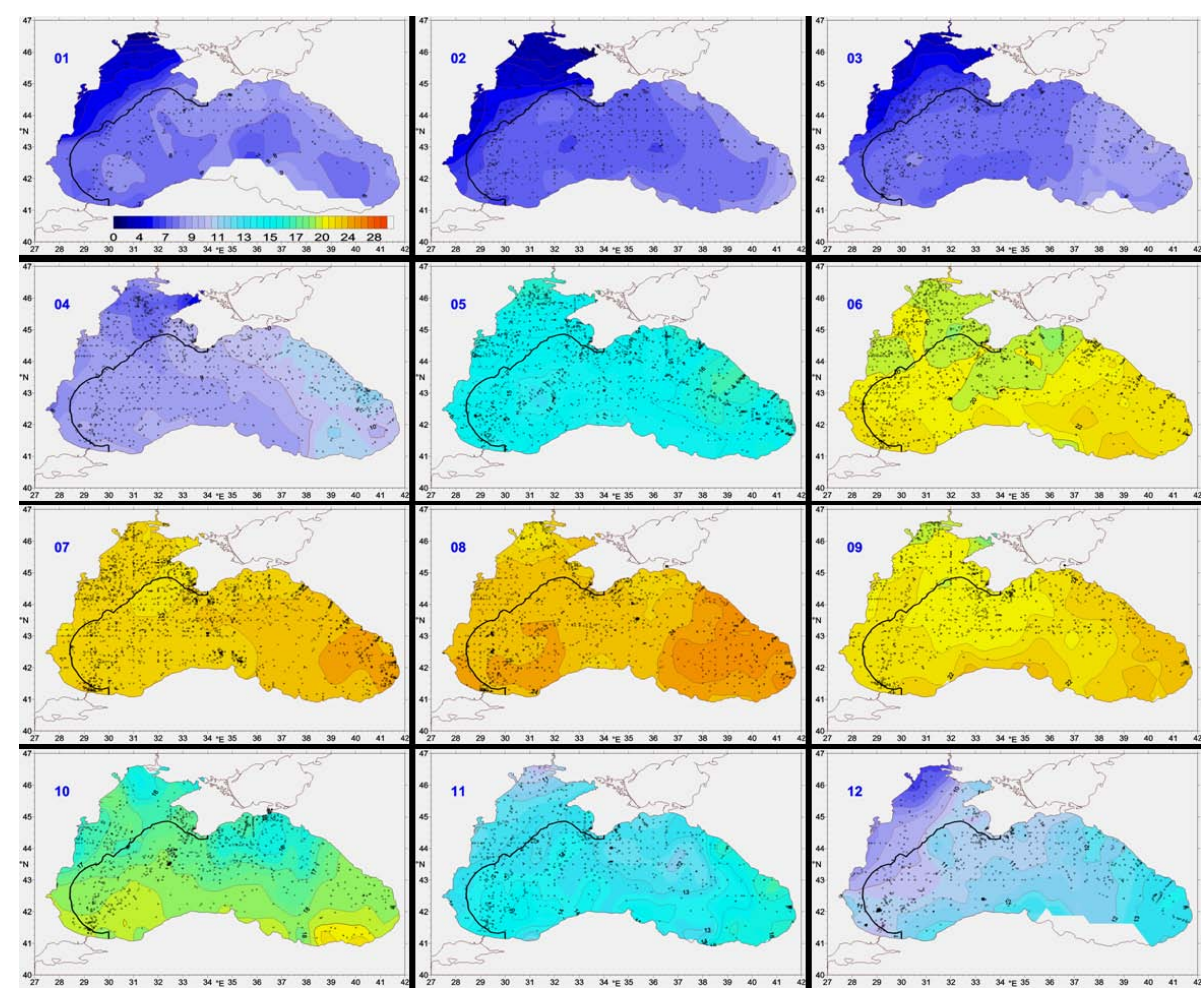

Fig. 4. Monthly charts of mean Sea Surface Temperature averaged over the 20th century.

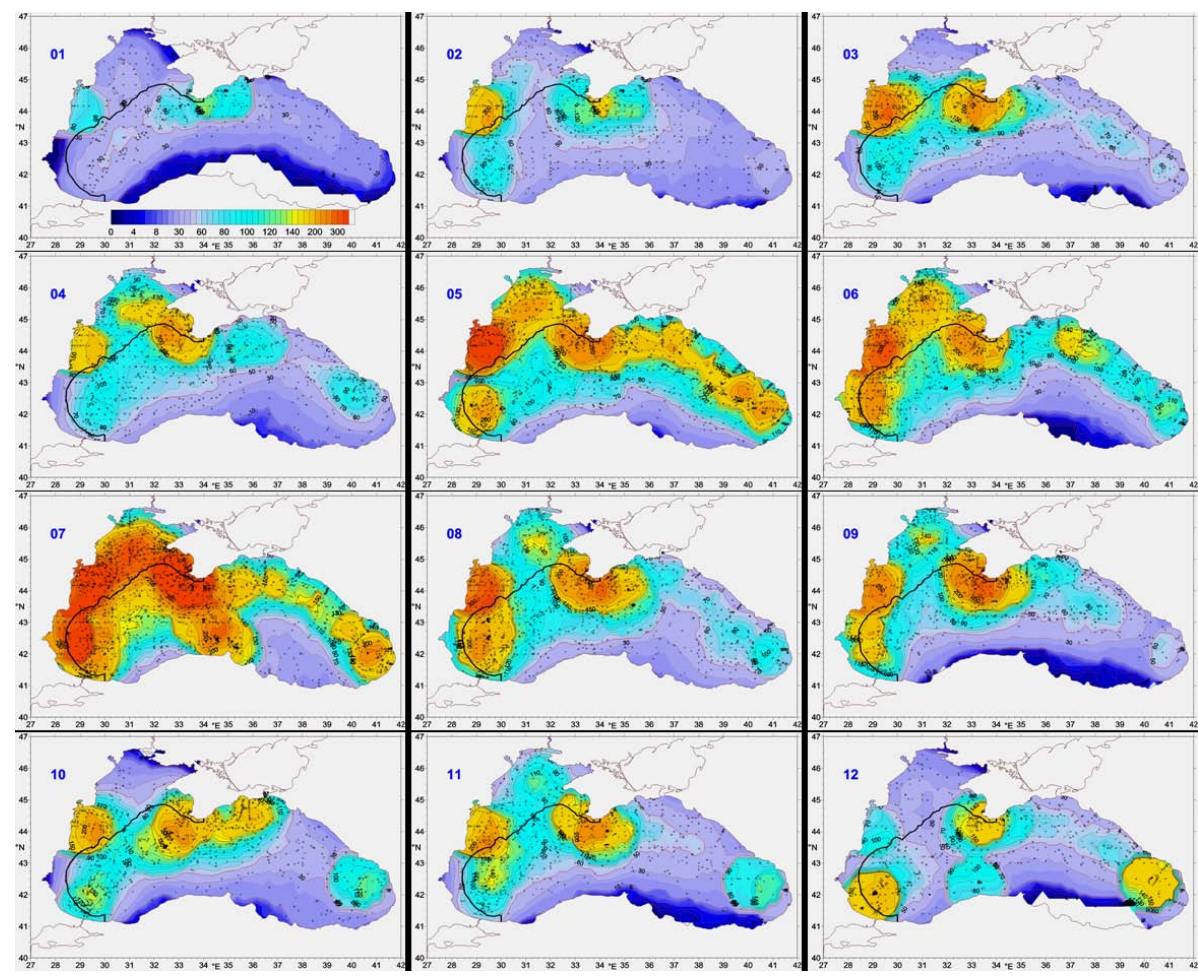

Fig. 5. Monthly charts of the distribution of the number of stations used for calculation climatic averages in Fig. 4. 
The monthly composite time series were then averaged over the whole period of observation to provide 12 monthly mean climatic maps using the equation

$$
<T(x, y, m)>=\frac{\sum_{i=1}^{n(x, y, m)} T(x, y, m, i)}{n(x, y, m)}
$$

where $n$ is the number of members in the time series containing actual measurements, the value of $n$ is dependent on the location $(x, y)$ and the calendar month, $m$.

Then the maps were processed with a 5-point matrix spatial smoother to reduce high frequency noise to produce monthly climatologies which are used for further analysis. The resulting charts are shown in Fig. 4.

As it was noted by Lozier et al. (1995) in order to achieve a good quality climatic map, the number of data points used for calculating climatology at each grid point should greater than 10. Figure 5 shows the distribution of data points per grid node used to produce monthly climatologies. The figure shows that a typical number of stations per grid node are 100-150 well above the recommended threshold.

The uncertainties in climate values are assessed by standard errors of the mean $\operatorname{err}(x, y, m)$ which are calculated for each monthly map at each grid node using the standard equation

$\operatorname{err}(x, y, m)=\frac{\sqrt{\sum_{i=1}^{n}\left(T_{\mathrm{p}}(x, y, m, i)-<T(x, y, m)>\right)^{2}}}{n}$

The errors are relatively small and typically less than $0.2^{\circ} \mathrm{C}$, i.e. significantly smaller than inter-decadal variability, see Fig. 6 and Sect. 3.

\subsection{Interannual and interdecadal variability}

The long-term variability in the SST was assessed using the spatially aggregated temperature anomalies, i.e. deviations of actual observations from the relevant climatology. The climatic mean at the each sampling site was obtained by interpolation from the neighbouring $0.25^{\circ}$ climate gridnodes for the appropriate month. The temperature anomaly for each station was then calculated as the difference between the actual observation and the climatic mean. The Black Sea was subdivided into 2 geographical provinces (Fig. 2), one including the biologically productive western shelf, i.e. areas shallower than $200 \mathrm{~m}$ and spread as far as $30^{\circ} \mathrm{E}$ along the southern coast and $34^{\circ} \mathrm{E}$ along the northern coast (hereafter referred WS). The other province (hereafter referred DS) covers the rest of the sea, mostly the deep sea areas. Data from the narrow (order of a few $\mathrm{km}$ ) shelves bordering the deep areas were consolidated with the data from the deep sea due to extensive exchanges between these areas. The monthly time series of SST anomalies for each of the provinces were obtained by averaging temperature anomalies from individual stations within each of the
12 (month) $\cdot 90$ (years) $=1080$ months over the corresponding province.

The advantage of consolidation of anomalies rather than the original observational data for providing a meaningful estimate of interannual changes is that the geographically inhomogeneous climatic mean is removed and so is the bias towards the locations with greater amount of observations. Another reason to aggregate anomalies, rather than absolute temperature is that absolute temperature varies markedly in short distances, while monthly temperature anomalies are representative of a much larger region (Hansen and Lebedeff , 1987).

\section{Results and analysis}

As expected, the $0.25^{\circ}$ climatology preserves the main qualitative features of temperature distribution calculated with coarser resolution (e.g., Stephens et al., 2002; Suvorov et al., 2004; Rayner et al., 2003). However, the higher resolution climatology shows up or represents more clearly local features such as coastal upwelling near the Bulgarian coast, spring warming on the NW shelf and a warm patch associated with the sub-basin gyre in the eastern Black Sea.

\subsection{Linear trends}

The SST anomaly time series for the deep Black Sea and the western shelf are shown in Fig. 7a, b. Due to large amount of monthly data points only yearly averaged SST anomalies are represented in Fig. 7a, b, while the statistical calculations below are done with the complete data set of monthly anomalies. Corresponding time series for surface air temperature at Odessa and Yalta weather stations are shown in Fig. 7c, d.

There are a number of statistical approaches for detecting and estimating trends that may be present in environmental variables (Hessa et al., 2001). Here the SST trends were estimated with both parametric and non-parametric statistical methods by calculating coefficients of linear regression, as well as Pearson, Spearman and Kendall-tau correlations (see Table 1). The correlation coefficients were calculated between the temperature data and the corresponding times of observations expressed in months elapsed from January 1900.

All four statistical methods clearly show that there was a definite cooling trend in the deep Black Sea over the 20th century (see Table 1). Linear regression analysis yields a negative rate of $(-0.86 \pm 0.3)^{\circ} \mathrm{C}$ per 100 years (see Fig. 7b) with the level of confidence as high as $\mathrm{CL}=(1-$ p) $\cdot 100 \%=98 \%$, where the $\mathrm{p}$-value is the probability to reject the null hypothesis. The confidence level of negative correlation obtained by non-parametric methods is also above the $\mathrm{CL}=98 \%$ mark.

On the western shelf the temperature trend is much less definitive. Whilst linear regression seem to show a small 


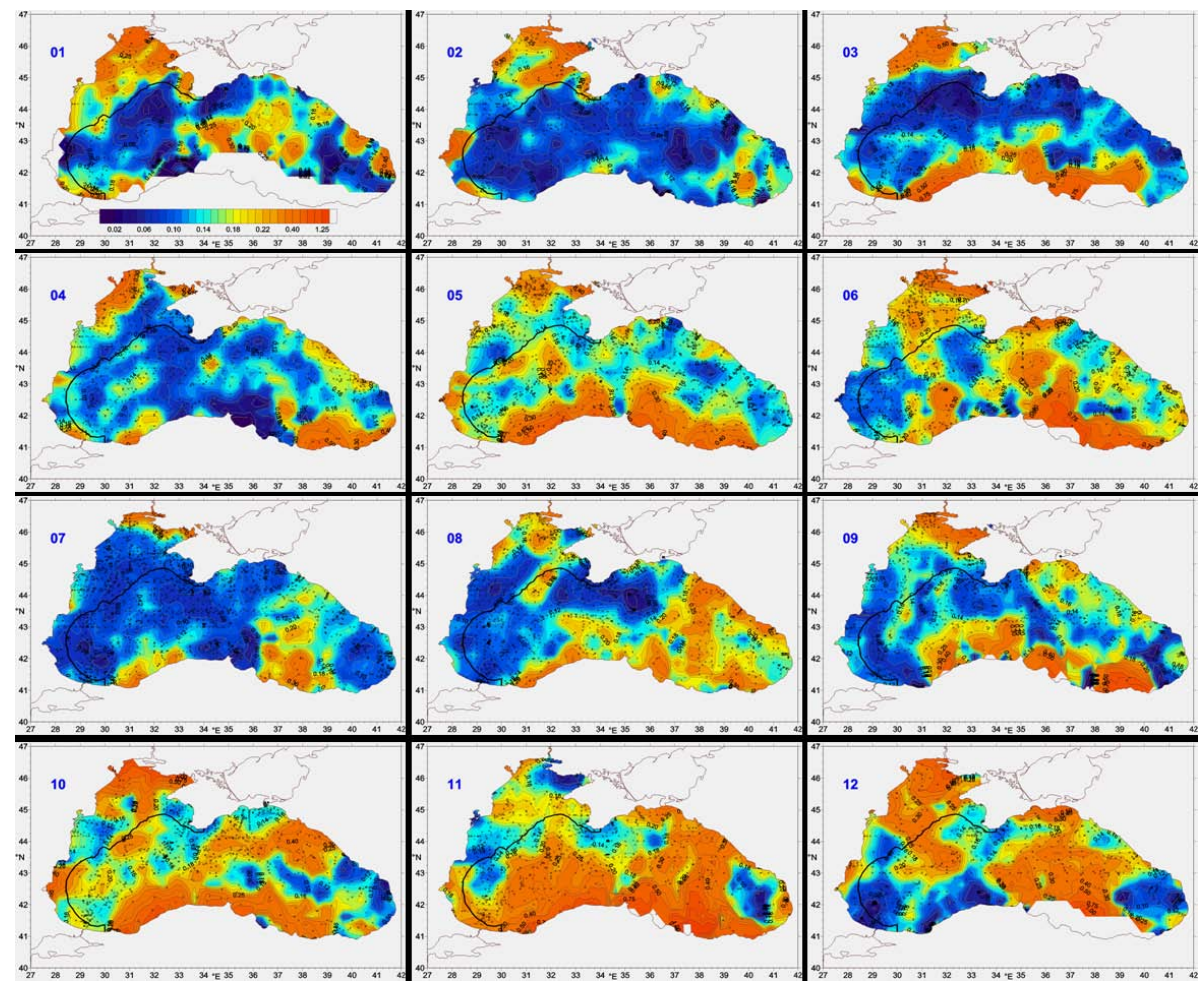

Fig. 6. Monthly charts of statistical uncertainties (in ${ }^{\circ} \mathrm{C}$ ) in calculation of the mean Sea Surface Temperature distributions shown in Fig. 4.

cooling trend of $(-0.2 \pm 0.3)^{\circ} \mathrm{C}$ per 100 years, it is not statistically significant as the level of confidence is very low (less than 40\%). This result was confirmed by other 3 methods (see Table 1), all showing a small negative correlation, which however is statistically indistinguishable from zero at the confidence level of $\mathrm{CL}=95 \%$. Hence there was neither cooling nor warming trend over the length of the 20th century on the Western shelf.

The linear trend in the air temperature in the central Black Sea represented by the data set from Yalta weather station is negative showing a modest whilst statistically significant cooling at $(-0.3 \pm 0.1)^{\circ} \mathrm{C}$ per 100 years. In contrast to this, air temperature in the western Black Sea measured at Odessa weather station shows a positive trend at $(0.3 \pm 0.2)^{\circ} \mathrm{C}$ per 100 years. Potential causes and consequences of the opposite trends in the western and central parts of the sea are discussed below.

\subsection{Interannual and interdecadal variability}

In addition to the overall trends over the whole century, a further analysis using the cumulative sum (CUSUM) method has been carried out on an interannual and decadal scale. The CUSUM method is considered particularly useful for identification of regime shifts, as well as small and sustained changes or slow fluctuations in the mean values, see e.g. (Yi et al., 2006, and references therein).
The CUSUM charts are shown in Fig. 8. A segment on a CUSUM chart with an upward slope indicates a period where the monthly mean temperature values tend to be above the climatic average. The downward slope indicates a period where those values tend to be below the average. Change in the slope of CUSUM charts manifests the regime shift.

Figure $8 \mathrm{~b}$ shows the CUSUM chart for area- aggregated monthly SST anomalies in the deep sea. Significant changes in slope of the graph, indicating regime shifts, are seen in years 1927, 1966, 1968, 1986 and 1997. The 1920s were "warm" years with high positive SST anomalies, the fact which is represented in Fig. 8b as a steeply rising section of the chart. The counterpart CUSUM chart for air temperature in Yalta shows only a small warming trend between 1922 and 1927 surrounded by negative and positive fluctuations of monthly air temperatures, see Fig. 8d.

The period from late 1940s to 1966 is characterized by a nearly constant value of CUSUM, which correlates with relatively small interchanging positive and negative SST anomalies. These were the "average" years exemplifying a cooldown development from the warm 1920s. During the same period, the air CUSUM chart (Fig. 8d) shows a series of fluctuations without any large peaks. The situation changes dramatically within the period 1960-1968 when air temperatures are subject to fast warming. The response of SST in the deep sea is lagged showing a fast and short warming in 1966 to 1968 which then is transformed into slow cooling until 

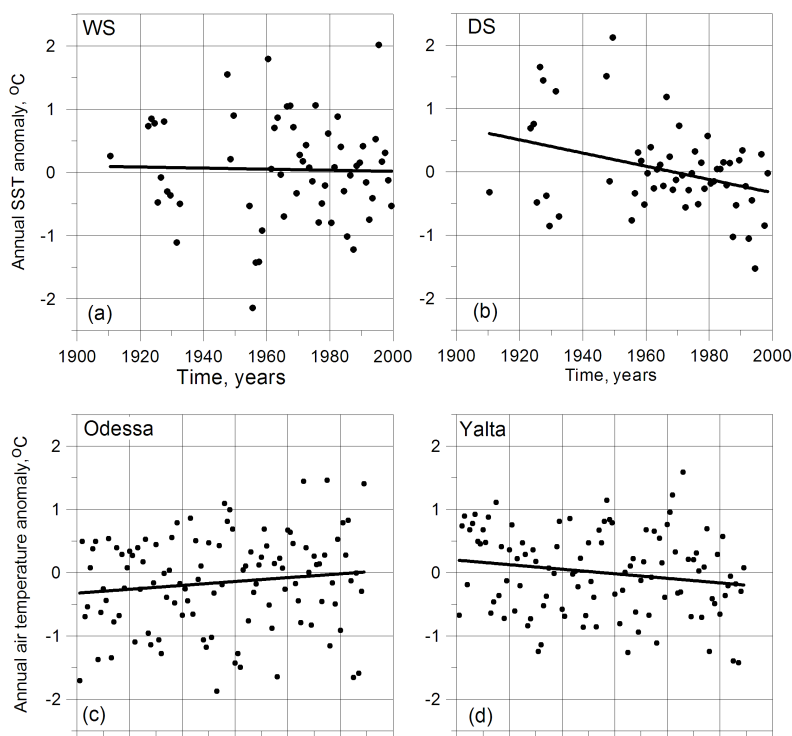

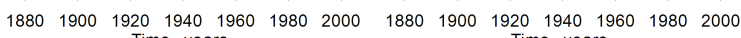

Fig. 7. Annual SST anomalies on the western shelf (a); deep sea (b); and air temperature anomalies for coastal stations Odessa (c); and Yalta (d). Temperature trends $\left(-0.17\right.$ (a), -0.86 (b), +0.31 (c) and -0.36 (d) ${ }^{\circ} \mathrm{C}$ per 100 years) are calculated using more detailed data of monthly anomalies, which are not shown to keep the graphs uncluttered.

Table 1. Statistics of the Sea Surface and Air Temperature trends.

\begin{tabular}{|c|c|c|c|c|c|c|c|c|c|c|}
\hline $\begin{array}{l}\text { TIME- } \\
\text { SERIES }\end{array}$ & TREND & $\begin{array}{r}\text { STD-ERROR } \\
\text { OF } \\
\text { TREND }\end{array}$ & $\begin{array}{r}\text { p-VALUE } \\
(2 \text {-tail })\end{array}$ & $\begin{array}{r}\text { PEARSON } \\
\text { CORRELATION } \\
\text { COEFFICIENT }\end{array}$ & $\begin{array}{r}\text { p-VALUE } \\
(2 \text {-tail) }\end{array}$ & $\begin{array}{r}\text { SPEARMAN } \\
\text { CORRELATION } \\
\text { COEFFICIENT }\end{array}$ & $\begin{array}{r}\text { p-VALUE } \\
(2 \text {-tail })\end{array}$ & $\begin{array}{r}\text { KENDALL-TAU } \\
\text { CORRELATION } \\
\text { COEFFICIENT }\end{array}$ & $\begin{array}{r}\text { p-VALUE } \\
(2 \text {-tail })\end{array}$ & $\begin{array}{r}\text { Confidence } \\
\text { level of the } \\
\text { trend }(\%)\end{array}$ \\
\hline DS, 1900-2000 & -0.008 & 0.003 & 0.015 & -0.125 & 0.015 & -0.128 & 0.012 & -0.086 & 0.012 & 98.5 \\
\hline WS, 1900-2000 & -0.002 & 0.003 & 0.603 & -0.024 & 0.603 & -0.051 & 0.264 & -0.035 & 0.250 & $<40$, insignificant \\
\hline DS, 1900-1984 & -0.008 & 0.005 & 0.101 & -0.112 & 0.101 & -0.078 & 0.252 & -0.049 & 0.280 & 90.0 \\
\hline DS, 1985-2000 & 0.048 & 0.034 & 0.169 & 0.137 & 0.169 & 0.012 & 0.901 & 0.008 & 0.908 & 83.0 \\
\hline WS, $1900-1984$ & 0.001 & 0.004 & 0.824 & 0.012 & 0.824 & -0.024 & 0.656 & -0.017 & 0.630 & $<20$, insignificant \\
\hline WS, 1985-2000 & 0.063 & 0.034 & 0.064 & 0.164 & 0.064 & 0.146 & 0.099 & 0.097 & 0.102 & 93.0 \\
\hline $\begin{array}{l}\text { Air Temp. Odessa, } \\
1881-1989\end{array}$ & 0.003 & 0.002 & 0.099 & 0.046 & 0.099 & 0.034 & 0.220 & 0.022 & 0.225 & 90.0 \\
\hline $\begin{array}{l}\text { Air Temp. Yalta, } \\
\text { 1881-1989 }\end{array}$ & -0.003 & 0.001 & 0.012 & -0.070 & 0.012 & -0.075 & 0.007 & -0.050 & 0.007 & 90.0 \\
\hline
\end{tabular}

1986. A similar slow cooling represented by a nearly constant value of CUSUM is seen in the air temperature from 1968 to 1975.

An intensive cooling phase in the air temperature in Yalta starts from 1975 until the end of the available for analysis data set (November 1989). The strong cooling phase in SST starts about a decade later probably triggered a severe winter of 1985 (Belokopytov, 1998). From the mid 1980s the CUSUM chart (Fig. 8b) shows an abrupt drop caused by a succession of "cold" years with negative SST anomalies (see Fig. 7b). Whilst there is similarity in the shape of the CUSUM charts for air temperature in Yalta and sea temperature in the deep sea they are far from identical and show a varying time lag between changes in the atmosphere and ocean.
The CUSUM charts for the western shelf shows a higher level of variability, see Fig. 8a The steep rise (warming) in the early 1920s is followed by a steep fall (cooling) in the late 1920s-early 1930s. This is out of phase with the warming trend in air temperature at Odessa (Fig. 8c), between 1914 and 1920 which was followed up by cooling in the period 1920-1922 and subsequent warming in 1922-1927. After some period (mid 1930s to late 1940s) where data were too sparse to make definitive conclusion the SST CUSUM chart shows a deep trough in 1958-1959 representing a cooling trend in the 1950s, which is followed by a positive peak in 1975 representing warming between 1959 and 1975. These variations are in phase with the tendencies in air temperature: fast cooling in 1953-1959 and a general warming (with some fluctuations) in the period 1960-1975. Further changes in air and sea are much more correlated: a sharp minimum at 


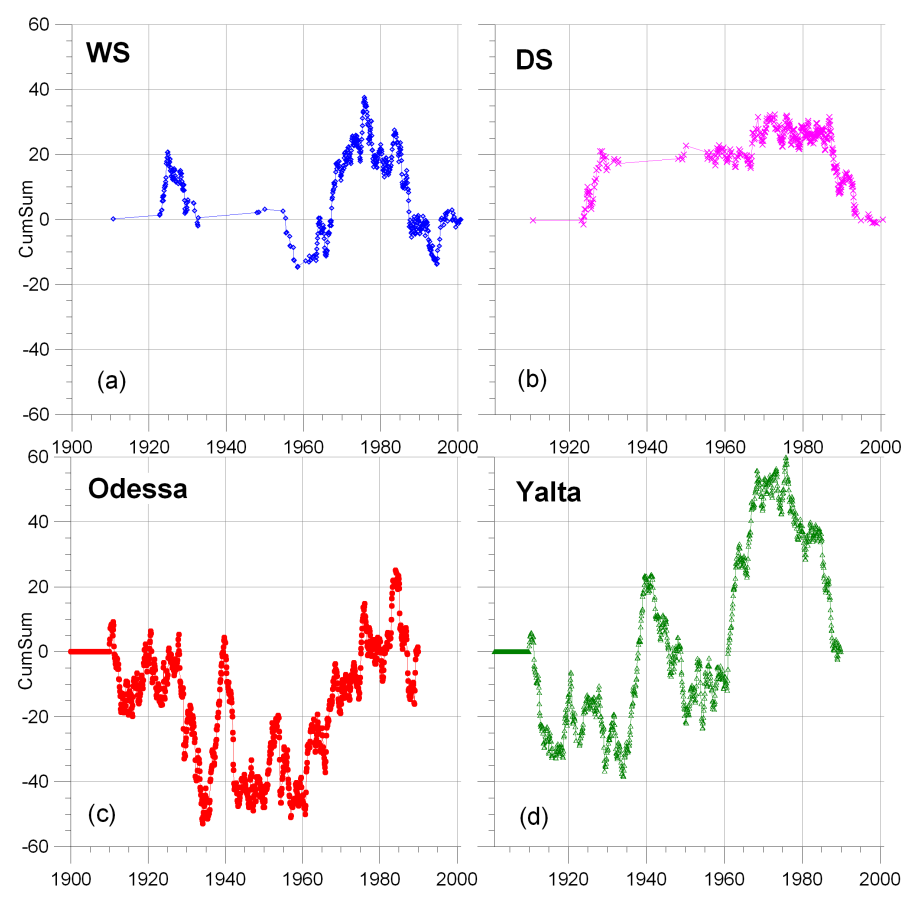

Fig. 8. The CUMSUM charts for aggregated temperature anomalies on the western shelf (a) and deep sea (b), and the CUMSUM charts for air temperature anomalies at coastal stations Odessa (c) and Yalta (d).

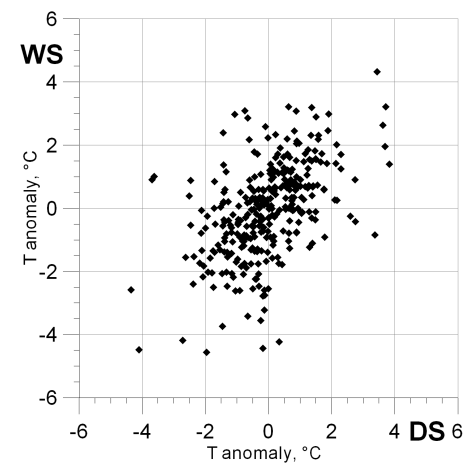

Fig. 9. A scatter plot showing distribution of SST anomalies on the Western shelf against SST anomalies in the deep sea.

around 1980 representing a cooling tendency between 1975 and 1980 is seen in both charts as well as local maximum in 1983-1984 (warming between 1980 and 1983) and another minimum - in 1989 for air and in 1993 for water showing the cooling tendency in late 1980s. A warming trend towards the end of century is also evident in both air and water temperatures.

The most significant cooling periods of the SST on the Western Shelf are associated with the most severe winters observed in 1947, 1954, 1985 and 1987. These winters were caused by frequent cold air outbreaks from the Arctic Ocean (Belokopytov, 1998). A cold but slightly milder winter of 1963 caused by penetration of air masses from Scandinavia did not cause similar changes in the thermic regime of either shelf or deep sea waters. However while the severe winters were followed by relatively mild weather conditions in the subsequent years, the cooling events in the shelf waters were extended over a number of years ( 8 years in the $1950 \mathrm{~s}$ and 5 years in the 1980s), which indicates a non-linear link between atmospheric forcing and the sea response: shortlived but severe weather events trigger longer term changes in the marine environment. Similar effect, however less pronounced, is seen in the deep sea. Generally response of the deep sea contains lower frequency components than the air temperature (see Fig. $8 b$ and d), which is manifestation of a greater heat capacity of the sea water.

The link between changes in the atmospheric conditions and the response of the sea can be seen from calculation of Pearson correlation between air and sea temperature anomalies both on shelf and deep sea. Calculations were carried out for the period 1910-1989 for those months when both monthly air and sea temperatures were available. Monthly data were pre-smoothed with a 6-month moving average filter to remove higher frequency oscillation. Results show amazingly similar level of correlations between local air and sea temperatures for both the deep sea and shelf regions: $\mathrm{R}(\mathrm{DS}$, air-SST $)=0.654$ for $\mathrm{DS}$ and $\mathrm{R}(\mathrm{WS}$, air-SST $)=0.652$ for WS. This result is underpinned by high correlations between the corresponding CUSUM charts for the original nonsmoothed time series - in the DS region R(CUSUM, air$\mathrm{SST})=0.826$, in the WS region $\mathrm{R}(\mathrm{CUSUM}$, air-SST $)=0.845$. Cross-correlation between the SST temperatures in shelf and 
deep sea regions is lower $\mathrm{R}(\mathrm{SST}$, DS-WS $)=0.506$, which is lower than correlation coefficient between air temperature anomalies from Odessa and Yalta $\mathrm{R}$ (air, Od-Ya) $=0.808$. This fact supports the statement of decoupling between the shelf and the deep sea waters, see Fig. 9.

\section{Discussion}

The long term variability in both deep and shelf areas of the Black Sea is at variance with many other parts of the world ocean (Levitus et al., 2005, 2009). General temperature variations in the Northern Hemisphere show little sign of trends before about 1900, a peak in the early 1940s, and the highest temperatures occurring after 1980 with overall positive (warming) trend over the 20th century (Parker et al., 1994). According to Kushnir (1994), the annual SST in the North Atlantic in the latitude belt $40-50^{\circ} \mathrm{N}$ between 1920 and 1987 has risen by $0.65^{\circ} \mathrm{C}$ at a rate of $0.97^{\circ} \mathrm{C}$ per 100 years. In the deep Black Sea, located within $42-47^{\circ} \mathrm{N}$, i.e. approximately at the same latitude, the trend for the same period was negative at $-0.86 \pm 0.3^{\circ} \mathrm{C}$ per 100 years in the deep sea and no statistically significant trend was identified on the western shelf.

Unusual temperature trends in the Black Sea could be attributed to the variations in the overlying weather pattern. The atmospheric forcing across the Black Sea is not uniform: the northern and north eastern parts of the sea are influenced by the atmospheric conditions of a moderate climate with relatively large inter-seasonal variations of meteorological parameters brought by the Siberian anticyclone, which is the source of very cold winds from the NE in the winter. The southern and south western parts are influenced by the milder Mediterranean weather system intruding from the southwest, and they belong to the sub-tropical climate zone with warm rainy winter and hot summer (Sukhovey, 1986).

The balance between the two weather systems is controlled by comparative strength of the westerly winds over Southern Europe, which can be represented by the values of the North Atlantic Oscillation Index (NAOI). A decrease in the NAOI from 1900 to 1984 at a rate of -1.3 units per 100 years (Jones et al., 1997) is linked with the reduction of the westerly winds over the Mediterranean and Southern Europe (Hurrell et al., 1997). The weakening of the westerlies could arguably shift the balance towards greater influence of the Siberian anticyclone over larger areas of the sea, not only its $\mathrm{NE}$ areas. The strengthening of the Siberian weather system is evidenced by a cooling trend in the air temperature at Yalta meteorological station (see Table 1) located close to the central part of the sea. In particularly cold years the influence of the Siberian anticyclone is seen further south. The "cold years" of the 1980s (1982, 1985 and 1987) were identified both in air and sea surface temperatures in the localised areas at the centre of the Black Sea $\left(\mathrm{a} 2^{\circ} \times 2^{\circ}\right.$ square centred at $\left.29^{\circ} \mathrm{E} 43^{\circ} \mathrm{N}\right)$ and in the Levantine Basin $\left(\right.$ a $2^{\circ} \times 2^{\circ}$ square centred at $29^{\circ} \mathrm{E} 35^{\circ} \mathrm{N}$ ) by Ozsoy and Unluata (1997) based on the comprehensive ocean-atmosphere data set (COADS). The extreme cooling of the 1987 was evidenced in the neighbouring southern areas e.g. dense water intrusion from the Aegean into the Marmara Sea (Besiktepe et al., 1994). In the western Black Sea, out of reach of the Siberian anticyclone, the air was warming in accordance with the general trend observed over the North Atlantic Ocean, see data from Odessa station in Fig. 3c.

A relatively small $(R=0.65)$ correlation coefficient between variations in air and sea temperatures for both DS and WS regions exemplifies a non-linear response of the sea to changing weather conditions. The analysis of CUSUM charts suggests that it is the shifts in the established weather regimes on a decadal scale rather than interannual variations of meteorological forcing which lead to changes between warming and cooling phases of SST evolution, particularly in the shelf regions (see Fig. 8a and c). The shelf and the deep sea response show different patterns of their responses to the weather conditions, which results in de-coupling of the SST variations of on the western shelves and the deep sea.

Comparison of presented results with other studies conducted for the second half/last quarter of the 20s century shows both general and quantitative agreement. The cooling trend of Sea Surface Temperature was noticed on a repeated transect taken within a 30-year period (1960-1990) in the western deep Black Sea (Polonsky and Lovenkova, 2004) in agreement with our results showing a cooling phase between 1968 and 1986 after a nearly decade of a warming trend (1960-1968). The warming trend which according to our CUSUM analysis started in the 1990s is in agreement with analysis based on satellite imagery (Ginzburg et al., 2004).

Variations in the physical parameters of the sea are coincident with the changes in the chemical properties. In the deep sea the nitrate level increased between 1960s and 1984 (Yunev et al., 2007) which coincides with the period of fast warming in 1960-1968 and then a period of thermic stability of relatively warm, slightly cooling surface waters (1968 to 1986). Yunev et al. (2007) report that the nitrate level in the open Black Sea increased until 1984/85 and the average maximum nitrate concentration and the nitrate gradient for all depth profiles increased between 1969 and 1984 and then remained constant. Strong cooling of the deep sea in the late 1980s coincides with stabilization of the nitrate concentration so that only moderate fluctuations in the nitrate profile characteristics were observed within this period. While it is common to associate changes in the Black sea nutrient concentration with variations in river discharges, and particularly level of eutrophication due to the Danube river, Yunev et al. (2007) indicate that some physical factors, such as intensification of the Rim Current, may play a role. Analysis of temperature anomalies presented here shows some parallelism in the variations of the SST and nitrates in the deep sea and it may not be accidental. Heat and nutrient dissipation are closely related and driven by physical processes. In 
the deep Black Sea vertical transport of cold water and nutrients is largely determined by winter storminess.

\section{Conclusions}

The use of an adaptive grid method with a two-scale covariance function allows calculation of monthly climatologies for the whole Black Sea over the 20th century with high spatial resolution of $0.25^{\circ}$ in both latitude and longitude and also allows separation of the properties of the western shelf waters from the deep sea. Analysis of the time series has revealed de-coupling between the shelf and deep sea regions of the sea in response to climate change. The deep sea experienced general cooling over the 20th century, which was particularly strong from beginning of century to late 1960s. The western shelf did not show a definite trend, except the last 1520 years when warming was evident in the SST time series. The changeover between cooling and warming trends took place in the 1990s and coincided with the dramatic regime shift in the Black sea ecosystem. This correlation has considerable potential to explain some of the major ecosystem changes that have recently occurred in the offshore Black Sea. Regime shifts may have been a significant historical feature of the offshore system because of the Black Sea's geographical location at the boundary between marine and continental climate systems.

Acknowledgements. This work was partly supported by the projects: FP6 SESAME project (grant EU-036949-2), FP6 ELME, FP7 MyOcean (project No FP7-SPACE-2007-1), FP7 HYPOX (project No 226213), RFBR grant 07-05-00240 and the NATO Environmental Security Project ESP.NUCR.CLG.982285. The authors are grateful to G. Borisyuk for discussions on statistics and to A. Cociasu for temperature records on the Romanian shelf.

Edited by: E. J. M. Delhez

\section{References}

Belokopytov, V.: On hydrometeorological conditions of Cold Intermediate Water renewal in northern part of the Black Sea, in: Ecosystem Modelling as a Management Tool for the Black SeaNATO ASI Ser. 2, edited by: Ivanov, L. and Oguz, T., Editors, Kluwer Academic Publishers, Dordrecht, 47-52, 1998.

Besiktepe, S., Sur, H. I., Özsoy, E., Latif, M. A., Oguz, T., and Ünlüata, Ü.: The Circulation and Hydrography of the Marmara Sea, Prog. Oceanogr., 34, 285-334, 1994.

Boyer, T. P., Levitus, S., Garcia, H., Locarnini, R. A., Stephens, C., and Antonov, J.: Objective analyses of annual, seasonal, and monthly temperature and salinity for the world ocean on a $0.25^{\circ}$ grid, Int. J. Climatol., 25, 931-945, doi:10.1002/JOC.1173, 2005.

Conversi, A., Peluso, T., and Fonda-Umani, S: Gulf of Trieste: A changing ecosystem, J.Geophys. Res., 114, C03S90, doi:10.1029/2008JC004763, 2009.
Daskalov, G. L.: Long-term changes in fish abundance and environmental indices in the Black Sea, Mar. Ecol. Prog. Ser., 255, 55-63, 2003.

Folland, C. K. and Parker, D. E.: Correction of instrumental biases in historical sea surface temperature data, Q. J. Roy. Meteorol. Soc., 121, 319-367, 1995.

Ginzburg, A. I., Kostianoy, A. G., Sheremet, N. A.: Seasonal and interannual variability of the Black Sea surface temperature as revealed from satellite data (1982-2000), J. Mar. Systems. 52, 33-50, 2004.

Hansen, J. E. and Lebedeff, S.: Global trends of measured surface air temperature, J. Geophys. Res., 92, 13345-13372, 1987.

Hessa, A., Iyera, H., and Malm, W.: Linear trend analysis: a comparison of methods, Atmos. Environ., 35, 5211-5222, 2001.

Hurrell, J. W. and van Loon, H.: Decadal variations in climate associated with the North Atlantic oscillation, Climatic Change, 36, 301-326, 1997.

Jones, P. D., Jónsson, T., and D. Wheeler: Extension to the North Atlantic Oscillation using early instrumental pressure observations from Gibraltar and South-West Iceland, Int. J. Climatol., 17, 1433-1450, 1997.

Jones, P. D., Osborn, T. J., Briffa, K. R., Folland, C. K., Horton, E. B., Alexander, L. V., Parker, D. E., and Rayner, N. A.: Adjusting for sampling density in grid box land and ocean surface temperature time series, J. Geophys. Res., 106(D4), 3371-3380, 2001.

Kazmin, A. S., Zatsepin, A. G. and Kontoyiannis, H.: Comparative analysis of the long-term variability of winter surface temperature in the Black and Aegean Seas during 1982-2004 associated with the large-scale atmospheric forcing, Int. J. of Climatol., doi:10.1002/joc.1985, 2009.

Kideys, A. E.: Fall and Rise of the Black Sea Ecosystem, Science, 297(5586), 1482-1484, 2002.

Kushnir, Y.: Interdecadal variations in North Atlantic sea surface temperature and associated atmospheric conditions, J. Climate, 7, 141-157, 1994.

Levitus, S., Antonov, J. I., and Boyer, T. P.: Warming of the World Ocean, 1955-2003, Geophys. Res. Lett., 32, L02604, doi:10.1029/2004GL021592, 2005.

Levitus, S., Antonov, J. I., Boyer, T. P., Locarnini, R. A., Garcia, H. E., and Mishonov, A. V.: Global ocean heat content 1955-2008 in light of recently revealed instrumentation problems, Geophys. Res. Lett., 36, L07608, doi:10.1029/2008GL037155, 2009.

Lozier, M. S., Owens, W. B., and Curry, R. G.: The climatology of the North Atlantic, Prog. Oceanogr., 36(1), 1-44, 1995.

McQuatters-Gollop, A., Mee, L. D., Raitsos, D. E., Shapiro, G.: Non-linearities, regime shifts and recovery: The recent influence of climate on Black Sea chlorophyll. J. Marine Syst., doi:10.1016/j.jmarsys.2008.06.002, 2008.

Mee, L. D., Friedrich, J., and Gomoiu, M. T.: Restoring the Black Sea in Times of Uncertainty, Oceanography, 18(2), 100-111, 2005.

Oguz, T.: Black Sea Ecosystem Response to Climatic Teleconnections, Oceanography, 18(2), 122-133, 2005.

Özsoy, E. and Ünlüata, Ü.: Oceanography of the Black Sea: A Review of Some Recent Results, Earth Sci. Rev., 42(4), 231-272, 1997.

Parker, D. E., Jones, P. D., Bevan, A., and Folland, C. K.: Interdecadal changes of surface temperature since the 19th century, J. 
Geophys. Res., 99, 14373-14399, 1994.

Polonsky, A. B. and Lovenkova E. A.: Temperature and salinity trends in the active layer of the Black Sea in the second half of the 20th century and their possible causes, Izv. RAN, Fizika atmosfery i okeana, 40(6), 832-841, 2004.

Rayner, N. A., Parker, D. E., Horton, E. B., Folland, C. K., Alexander, L. V., Rowell, D. P., Kent, E. C., and Kaplan, A.: Global analyses of sea surface temperature, sea ice, and night marine air temperature since the late nineteenth century, J. Geophys. Res., 108(D14), 4407, doi:10.1029/2002JD002670, 2003.

Reid, P. C., Borges, M. F., and Svendsen, E.: A regime shift in the North Sea circa 1988 linked to changes in the North Sea horse mackerel fishery, Fish. Res., 50, 163-171, 2001.

Shapiro, G. I. and Meschanov, S. L.: Spreading pattern and mesoscale structure of Mediterranean outflow in the Iberian Basin estimated from historical data, J. Marine Syst., 7, 337348, 1996.

Stephens, C., Antonov, J. I., Boyer, T. P., Conkright, M. E., Locarnini, R., and O'Brien, T. D.: World Ocean Atlas 2001. 1: Temperature (CD-ROM), edited by: Levitus, S., NOAA Atlas NESDIS 49, US Govt. Printing Office, Washington, DC, 2002.

Sukhovey, V. F.: The Seas of the World Ocean, Gidrometeoizdat, Leningrad, 288 pp., 1986.
Suvorov, A. M., Eremeev, V. N., Belokopytov, V. N., Khaliulin, A. H., Godin, E. A., Ingerov, A. V., Palmer, D. R., and Levitus, S.: Digital Atlas: Physical Oceanography of the Black Sea (CDROM), Environmental Services Data and Information Management Program, Marine Hydrophysical Institute of the National Academy of Sciences of Ukraine, 2004.

Willis, J. K., Roemmich, D., and Cornuelle, B.: Interannual variability in upper ocean heat content, temperature, and thermosteric expansion on global scales, J. Geophys. Res., 109, C12036, doi:10.1029/2003JC002260, 2004.

Yi, G., Coleman, S., and Ren, Q.: CUSUM method in predicting regime shifts and its performance in different stock markets allowing for transaction fees, J. Appl. Stat., 33(7), 647-661, 2006.

Yunev, O. A., Carstensen, J., Moncheva, S., Khaliulin, A., Ertebjerg, G., and Nixon, S.: Nutrient and phytoplankton trends on the western Black Sea shelf in response to cultural eutrophication and climate changes, Estuarine, Coast. Shelf Sci., 74, 63-76, 2007.

Zaitsev, Y. P. and Alexandrov, B. G.: Recent man-made changes in the Black Sea ecosystem, in: Sensitivity to Change: Black Sea, Baltic Sea and North Sea, edited by: Ozsoy, E. and Mikaelyan, A., Kluwer Academic Publishing, Dordrecht, The Netherlands, 25-31, 1997. 